\title{
Heart Failure in Children: Epidemiological, Etiological and Diagnostic Aspects in Diamniadio Children's Hospital (Senegal)
}

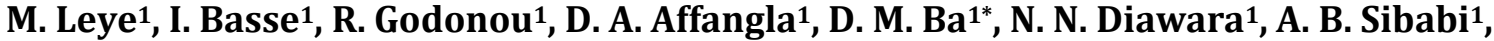

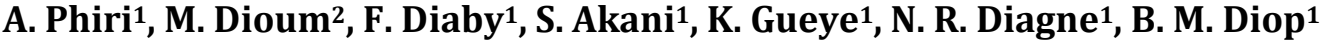 \\ ${ }^{1}$ Unité de Formation et de Recherche en sciences de la santé, Université de Thiès, Thiès, Sénégal \\ ${ }^{2}$ Faculté de Médecine de Pharmacie et d’odontologie, Université Cheikh Anta Diop de Dakar, Dakar, Sénégal \\ Email: leyemohamed@gmail.com, Idrissabasse@yahoo.fr, rosettegodonou@gmail.com, docalaf@gmail.com, \\ *gaby11.ba@gmail.yahoo.fr, ndiacoudoc@yahoo.fr, sibabialibidos@gmail.com, chiyambiphiri@gmail.com, \\ momar.dioum@yahoo.fr, diabyfalk@yahoo.com, akanniclaudia@yahoo.fr,khadi.aiie@gmail.com, \\ rama.diagne24@yahoo.fr, bmdiopmi@yahoo.fr
}

How to cite this paper: Leye, M., Basse, I., Godonou, R., Affangla, D.A., Ba, D.M., Diawara, N.N., Sibabi, A.B., Phiri, A., Dioum, M., Diaby, F., Akani, S., Gueye, K., Diagne, N.R. and Diop, B.M. (2020) Heart Failure in Children: Epidemiological, Etiological and Diagnostic Aspects in Diamniadio Children's Hospital (Senegal). World Journal of Cardiovascular Diseases, 10, 12-18. https://doi.org/10.4236/wjcd.2020.101002

Received: November 20, 2019

Accepted: January 13, 2020

Published: January 16, 2020

Copyright $\odot 2020$ by author(s) and Scientific Research Publishing Inc. This work is licensed under the Creative Commons Attribution International License (CC BY 4.0).

http://creativecommons.org/licenses/by/4.0/

\begin{abstract}
Introduction: Heart failure is a major cause of morbidity and mortality in children. The authors aimed to report the epidemiological and etiological characteristics of heart failure (HF) in children in Senegal. Patients and Methods: This was a retrospective study conducted at the Children's Hospital of Diamniadio (CHD) from 01-01-2016 to 31-12-2017. Children aged 0 to 15 years with heart failure confirmed by echocardiography were included. Results: Sixty-six children were admitted for heart failure. The prevalence of HF was $5.3 \%$. The mean age of the children was 41.59 months \pm 53.35 months (range: 0 to 168 months). The $0-5$ age group was the most represented ( $\mathrm{n}=$ $48 ; 72.72 \%)$. The HF concerned 38 boys and 28 girls, a sex ratio (M/F) of 1.36 . The majority of our patients came from the semi-urban area (42.4\%). The etiology of HF was represented in order of frequency by congenital heart disease, rheumatic heart disease and cardiomyopathy with $59.09 \%$ of cases, $22.73 \%$ of cases and $7.58 \%$ of cases respectively. It was unknown in $4.54 \%$ of the cases. At echocardiography, the left ventricular ejection fraction (LVEF) was impaired (less than $50 \%$ ) in 19 patients, in $29.2 \%$ of cases with an average of $64 \%+/-15.16 \%$ (extremes: $24 \%$ and $86 \%$ ). Anemia was the comorbidity most commonly associated with their condition ( $\mathrm{n}=33 \%$; $50 \%)$. Conclusion: Heart failure in children is uncommon. The main etiology is represented by congenital heart disease.
\end{abstract}

\section{Keywords}

Heart Failure, Children, Congenital Heart Disease, Senegal 


\section{Introduction}

Heart failure (HF) is an uncommon but serious syndrome in children representing a pejorative evolutionary modality of most heart diseases [1]. It is difficult to diagnose because of its clinical polymorphism and etiology, which varies considerably between different age groups. The diagnosis of heart failure also requires expertise in the sub-specialty of cardio-pediatric still insufficient in sub-Saharan Africa [2] [3]. Epidemiological data on children's HF are rare in Senegal. The authors aimed to report the epidemiological and etiological features of child heart failure at the children's hospital in Diamniadio, Senegal.

\section{Patients and Methods}

This was a retrospective study conducted at the Children's Hospital from 1 January 2016 to 31 December 2017. Were included, patients aged 01 days to 15 years admitted for heart failure syndrome confirmed by echocardiography. Sociodemographic data were collected by the interview of parents: the age in months from the date of birth and the rural or urban dwelling area according to the criteria of the National Agency of Statistics and Demography of Senegal [4]. The socio-economic level is judged according to the following subjective criteria: good if both parents work and have a regular income, average if only one of the parents works with a regular income, low if both parents do not work or do not have a regular income.

The clinical criteria for the diagnosis of HF from the Canadian cardiovascular society were used [5]. Echocardiography diagnostic criteria were the existence of a morphological anomaly and/or alteration of the Shortening Fraction (SF) < $28 \%$ or an Ejection Fraction (EF) $<50 \%$ and/or an elevation of blood pressure in the left atrium and/or in the right atrium. The new echocardiographic criteria of the World Heart Federation for the diagnosis of rheumatic valve disease were used [6]. Radiological cardiomegaly was retained when the Cardio-Thoracic Index (CTI) was $>0.60$ before 2 years and $>0.55$ after 2 years. The diagnosis of anemia was made for a hemoglobin level lower than normal value corresponding to age.

The collection of data from patients' records was done using a standardized form.

The records of patients with signs suggestive of heart failure but not containing data from an echocardiography were excluded.

The capture and statistical analysis of our data were performed using the software EPI INFO version 3.5.4. The validated data were entered on a microcomputer and analyzed using EPI Info software version 3.5.4 on Windows version 10.0. Qualitative data were represented as proportions (\%) and continuous variables as mean standard deviation (SD) with their extremes. The Pearson chi-square test and Fischer's exact test were used to compare the percentages. The unified risk of death was measured by odds ratio (OR) with $95 \%$ confidence interval (95\% CI) and the application of the Manthel-Haenzel chi-square test. 
The significance threshold is defined for a value of $p \leq 0.05$.

\section{Results}

During the study period, 66 children were admitted to the Diamniadio Children's Hospital (DCH) for heart failure out of 12.385 for a prevalence of $5.3 \%$. The mean age of the patients was 41.59 months \pm 53.35 months (range: 0 to 168 months). The age group [0 - 5] years was the most represented $(\mathrm{n}=48 ; 72.72 \%)$ followed by the $[5-10]$ years $(n=13 ; 19.7 \%)$ and the $[10-15$ years] $(n=5$; 7.6\%). The HF involved 38 boys and 28 girls, a sex ratio (M/F) of 1.36. Most of our patients came from the semi-urban area $(42.4 \%)$, followed by rural $(31.8 \%)$ and urban (25.8\%) The majority of patients in our work $(\mathrm{n}=33 ; 50 \%)$ came from families with low socioeconomic status, while very few $(n=4,6.1 \%)$ came from families with a good socioeconomic level. Majority of patients came from home $(\mathrm{n}=33 ; 50 \%)$ or intra-hospital transfer $(\mathrm{n}=32 ; 48.5 \%)$ and only one patient was from inter-hospital transfer (1.5\%). Nearly half of the patients (45.5\%) had a history of hospitalization for heart failure.

Radiological cardiomegaly was found in nearly all patients $(\mathrm{n}=61 ; 92.5 \%)$ with an ICT mean of $64.58 \%+/-11.32 \%$ (range: 55 to $80 \%$ ).

The etiology of heart failure was represented by order of frequency by congenital heart disease, rheumatic heart disease and cardiomyopathy with $59.09 \%$ of cases, $22.72 \%$ of cases and $13.64 \%$ of cases respectively. It was unknown in $4.54 \%$ of cases (Table 1).

Congenital heart diseases responsible for heart failure were represented in order of frequency by: ventricular septal defect $(\mathrm{n}=15 ; 38.46 \%)$, atrioventricular septal defect $(n=6 ; 15.38 \%)$, patent arterial ductus arteriosus $(n=6 ; 15.38 \%)$, atrial septal defect $(\mathrm{n}=2 ; 5.13 \%)$ and various combinations $(\mathrm{n}=10 ; 25.64 \%)$ (Table 2). At echocardiography, the left ventricular ejection fraction (LVEF) was impaired (less than 50\%) in 19 patients (28.78\%) with an average of $64 \%+/-$ 15.16\% (extremes: $24 \%$ and $86 \%$ ). Pulmonary arterial hypertension was common in children; found in 49 children in $74.24 \%$ of cases. Anemia was the comorbidity most commonly associated with their condition $(n=33 ; 50 \%)$.

\section{Comments}

The prevalence of children with heart failure in our study was $5.3 \%$. It was rare as reported in the literature [1]. Ngouala Ba et al. in Louga, Senegal found a hospital prevalence of infantile heart disease of $4.3 \mathrm{p} / \mathrm{ml}$ mainly revealed by heart failure [7]. On the other hand, N'Goran et al. in Abidjan find a hospital prevalence of $19.08 \%$ in a cardio-pediatric department [8]. The specialized nature of the service may explain this higher prevalence of heart failure.

The majority of patients in our work $(\mathrm{n}=33 ; 50 \%)$ came from families with low socioeconomic status, while very few $(n=4 ; 6.1 \%)$ came from families with a good socioeconomic level. This socio-economic profile of our patients could be explained by the regional location of our study site, the children's hospital of 
Table 1. Repartition of heart failure according to etiology.

\begin{tabular}{ccc}
\hline Etiology & Number & Percentage (\%) \\
\hline Congenital heart diseases & 39 & 59.09 \\
Rheumatic heart disease & 15 & 22.72 \\
Cardiomyopathy & 9 & 13.64 \\
Unknown & 3 & 4.54 \\
Total & 66 & 100 \\
\hline
\end{tabular}

Table 2. Repartition according to the type of congenital heart disease causing heart failure.

\begin{tabular}{ccc}
\hline Type of congenital heart disease & Number & Percentage (\%) \\
\hline Atrioventricular septal defect & 6 & 15.38 \\
Atrial septal defect & 2 & 5.13 \\
Ventricular septal defect & 15 & 38.46 \\
Patent ductus arteriosus & 6 & 15.38 \\
Associations & 10 & 25.64 \\
Total & 39 & 100.0 \\
\hline
\end{tabular}

Diamniadio, which is in a semi-urban area where the populations of low socioeconomic levels are majority [4].

The age group [0 - 5] years was the most represented in our work and would explain the greater prevalence of congenital heart disease, with rheumatic heart disease affecting children only exceptionally before the age of five [9]. On the other hand, the improvement of the diagnosis tools could also explain the earlier and more precise diagnosis of infantile heart disease, as evidenced by data from the recent literature [7] [10] [11] [12]. The low prevalence of rheumatic heart disease in our work, of $22.72 \%$, corroborated by the literature could also be explained by the beginning of the decline of rheumatic fever and rheumatic heart valve diseases due to the improvement of the standard of living of the populations and the access to health services. As proof, the Diamniadio Children's Hospital was inaugurated in 2012 and is receiving patients from semi-urban and rural areas who have access to specialized care, in this case, cardio-pediatrics. On the other hand, at the heart institute in Abidjan, rheumatic heart valve diseases remain the leading cause of heart failure in children with a prevalence of $31.71 \%$ and congenital heart diseases the second cause with $20.60 \%$ [8].

Clinically in our study as those of Ngouala Ba et al. in Louga in Senegal, Kinda in Ougadougou, and Mpemba in Brazzaville [7] [10] [12] dyspnea, the main symptom of heart failure, was the most common revealing circumstance of child heart disease.

An abnormal cardiac figure with radiological cardiomegaly was constantly found in our work. This important contribution of radiology for heart failure 
diagnosis was also reported by several authors at a frequency ranging from $83.5 \%$ to $97 \%$ [13] [14]. This is an inexpensive exploration that should as in our work act as an HF first-line diagnostic approach, especially in our countries where the echocardiography and the specialists are often concentrated in capitals. It was prescribed in 53 patients, $80.3 \%$ of cases. The ECG was seldom prescribed in our work, only in 11 patients, $16.7 \%$ of cases. This low ECG prescription, as in the work of Kinda et al. [10], may be explained by its low contribution to the heart failure diagnosis. On the other hand, it is an exploration that should be systematic because it could be contributory to the diagnosis of heart failure but especially to the etiological diagnosis and complications notably the rhythm and conduction disorders.

The important role of echocardiography in the diagnosis of congenital and acquired heart disease, especially rheumatic heart disease, is accepted by all authors [15] [16]. The biological markers of heart failure, the BNP and NT Pro BNP assay, which had not been used for the diagnosis of heart failure, would be of little contribution according to the literature [17].

The high prevalence of anemia, in one in two patients in our work, could be explained on one hand by the high prevalence of anemia in children in Africa [18], but also by the repercussions of dyspnea and hemodilution frequently observed during heart failure [19]. Moreover, the retrospective nature of our study did not allow us to search for rare etiologies of cardiomyopathies such as metabolic diseases, carnitine deficiency, hypocalcemia, hyperthyroidism, myocarditis [20].

\section{Conclusion}

Heart failure in children is uncommon. Chest X-ray, ECG, and echocardiography should be widely prescribed for any dyspnea in children to enable early diagnosis and management of heart disease before the onset of heart failure. Efforts must be maintained in the fight against rheumatic fever.

\section{Limits}

Those inherent in a retrospective study include lack of completeness of some data, including the ECG.

\section{Ethical Considerations}

Information gathered during the study of the medical records was treated on the spot and in all confidentiality.

\section{Conflicts of Interest}

The authors declare that they have no conflict of interest in connection with this study.

\section{References}

[1] Bressieux-Degueldre, S. and Sekarski, N. (2015) Insuffisance cardiaque chez 
l'enfant; reconnaitre et diagnostiquer. Paediatrica, 26, 12-14.

[2] Hewitson, J., Brink, J. and Zilla, P. (2002) The Challenge of Pediatric Cardiac Services in the Developing World. Seminary in Thoracic and Cardiovascular Surgery, 14, 340-345. https://doi.org/10.1053/stcs.2002.35298

[3] Réseau Vision Tokyo 2010 (2013) http://rvt2010.com/wp-content/uploads/2017/01/problématique-des-ressources-hu maines-en-santé-des-pays-membres-du-réseau-vision-Tokyo-2010.pdf

[4] Agence Nationale de la statistique et de la démographie du Sénégal. Enquête démographique et de santé continue 2012-2013. https://dhsprogram.com/pubs/pdf/FR288/FR288.pdf

[5] Kantor, P.F., et al. (2013) Presentation, Diagnosis and Medical Management of Heart Failure in Children: Canadian Cardiovascular Society Guidelines. Canadian Journal of Cardiology, 29, 1535-1552. https://doi.org/10.1016/j.cjca.2013.08.008

[6] Kane, A., Kingue, S. and Affangla, A. (2012) Les nouveaux critères du diagnostic échographique des valvulopathies rhumatismales. Les recommandations de la world heartfederation. Cardiologie Tropicale, 133, 1-5.

[7] Ngouala Ba, G.A.B., Affangla, D.A., Leye, M. and Kane, A. (2015) Prévalence des cardiopathies infantiles symptomatiques au Centre Hospitalier Régional de Louga, Sénégal. Cardiovascular Journal of Africa, 26, e1-e5.

https://doi.org/10.5830/CVJA-2015-031

[8] N'Goran, Y.N.K., Tano, M.A., Koffi, F., et al. (2019) Profil étiologique de l'insuffisance cardiaque de l'enfant à l'Institut de cardiologie d'Abidjan. Cardiologie Tropicale, 155, 1-7.

[9] World Heart Federation (2019) Diagnostic et prise en charge du rhuùatisme articulaire aigu et des cardiopathies rhumatismales chroniques.

http://www.institutpasteur.nc/wp-content/uploads/2012/09/2008-WHF-Diagnosticet-Prise-en-charge-du-RAA-et-des-CRC.pdf

[10] Kinda, G., Rosario, C.M.G., Koueta, F., et al. (2015) Cardiopathies congénitales: Aspects épidémiologiques et échocardiographiques à propos de 109 cas au centre hospitalier universitaire pédiatrique Charles de Gaulle (CHUP-CDG) de Ouagadougou, Burkina Faso. Pan African Medical Journal, 20, 81.

[11] Basse, I., Fall, A.L., Seck, N., et al. (2018) Les communications interauriculaires chez l'enfant: Diagnostic et prise en charge à propos de 49 cas aux $\mathrm{CHU}$ pédiatriques de Dakar. Pan African Medical Journal, 30, 245.

https://doi.org/10.11604/pamj.2018.30.245.14556

[12] M'PembaLoufoua Lemay, A.B., Johnson, E.A. and Nzingoula (2005) Les cardiopathies congénitales observées dans le service de pédiatrie Grands Enfants du CHU de Brazzaville à propos de 73 cas: Aspects épidémiologiques. Médecine d Afrique Noire, 52, 173-177.

[13] Pio, M., Afassinou, Y., Pessinaba, S., et al. (2014) Epidémiologie et étiologies des insuffisances cardiaques à Lomé. Pan African Medical Journal, 18, e183.

[14] Diallo, B., Sanogo, K., Diakité, S., et al. (2004) Insuffisance cardiaque à l'hôpital du Point G. Mali Médical, 2, 15-17.

[15] Kane, A., Mirabel, M., Touré, K., et al. (2013) Echocardiographic Screening for Rheumatic Heart Disease: Age Matters. International Journal of Cardiology, 168, 888-891. https://doi.org/10.1016/j.ijcard.2012.10.090

[16] Ellis, J., Martin, R., Wilde, P., Tometzki, A., Senkungu, J. and Nansera, D. (2007) Echocardiographic, Chest X-Ray and Electrocardiogram Findings in Children Presenting with Heart Failure to a Ugandan Paediatric Ward. Tropical Doctor, 37, 
149-150. https://doi.org/10.1258/004947507781524665

[17] Tissières, P. and Beghuetti, M. (2008) Biomarqueurs cardiaques en pédiatrie. Paediatrica, 19, 2.

[18] Diouf, S., Folquet, M., Mbofung, K., et al. (2015) Prévalence et déterminants de l'anémie chez le jeune enfant en Afrique francophone-Implication de la carence en fer. Archives de Pédiatrie, 22, 1188-1197. https://doi.org/10.1016/j.arcped.2015.08.015

[19] Keller, O., Mourot-Cottet, R. and Vogel, T. (2015) Anémie et insuffisance cardiaque. Étude de 317 patients. La Revue de Médecine Interne, 36, 20-21. https://doi.org/10.1016/j.revmed.2015.03.234

[20] Maalej, B., Gargouri, L. and Abid, D. (2018) La cardiomyopathie de l'enfant. J.I.M. Sfax, 29, 18-28. 